\title{
Medication review and
} reconciliation with

\section{cooperation between}

pharmacist and general

practitioner and the benefit for the patient: a systematic review

Correspondence

Mrs Marlies M. E. Geurts MSc PharmD, Department of Pharmacotherapy and Pharmaceutical Care, Research Institute SHARE, University of Groningen, Antonius Deusinglaan 1,9713 AV Groningen, The Netherlands.

Tel.: +310503632578

Fax: +3105036327 72

E-mail:mmegeurts@gmail.com

\section{Keywords}

family physician, interprofessional relations, patient care, pharmaceutical care, pharmaceutical services, pharmacist

\section{Received}

28 July 2011

Accepted

4 January 2012

Accepted Article

Published Online

13 January 2012
Johan J. de Gier ${ }^{1}$

${ }^{1}$ Department of Pharmacotherapy and Pharmaceutical Care, Research Institute SHARE, University of Groningen, Groningen, The Netherlands and ${ }^{2}$ Academic General Practice, University Medical Center Groningen, Groningen, The Netherlands

This article systematically reviews the literature on the impact of collaboration between pharmacists and general practitioners and describes its effect on patients' health. A systematic literature search provided 1041 articles. After first review of title and abstract, 152 articles remained. After review of the full text, 83 articles were included. All included articles are presented according to the following variables: (i) reference; (ii) design and setting of the study; (iii) inclusion criteria for patients; (iv) description of the intervention; (v) whether a patient interview was performed to involve patients' experiences with their medicine-taking behaviour; (vi) outcome; (vii) whether healthcare professionals received additional training; and (viii) whether healthcare professionals received financial reimbursement. Many different interventions are described where pharmacists and general practitioners work together to improve patients' health. Only nine studies reported hard outcomes, such as hospital (re)admissions; however, these studies had different results, not all of which were statistically significant. Randomized controlled trials should be able to describe hard outcomes, but large patient groups will be needed to perform such studies. Patient involvement is important for long-term success.

\section{Introduction}

To provide best pharmaceutical care practice, it is important that all relevant persons are involved and work together as a healthcare team [1,2]. As a result, healthcare providers should have a complete patient and medical record. Besides medical information from healthcare providers, a consultation round with the patient is also necessary to determine patients' problems and patients' needs. Active participation of patients during treatment could help to achieve better patient outcomes $[3,4]$. In primary care, the triangle of the pharmacist-general practitioner (GP)-patient is important for providing optimal pharmaceutical care. According to the definition of Cipolle et al., pharmaceutical care is 'a patient-centered practice in which the practitioner assumes responsibility for a patient's drug-related needs and is held accountable for this commitment' [5].

An important tool for pharmaceutical care is regular medication reviews or medication reconciliation next to the assessment of patient needs and the development of a care plan. A medication review is defined as 'a structured, critical examination of a patient's medicines with the objective of reaching an agreement with the patient about treatment, optimizing the impact of medicines, minimizing the number of medication-related problems and reducing waste' [6]. Medication reconciliation is defined as 'the process of obtaining and maintaining a complete and 


\section{Levels of medication review}

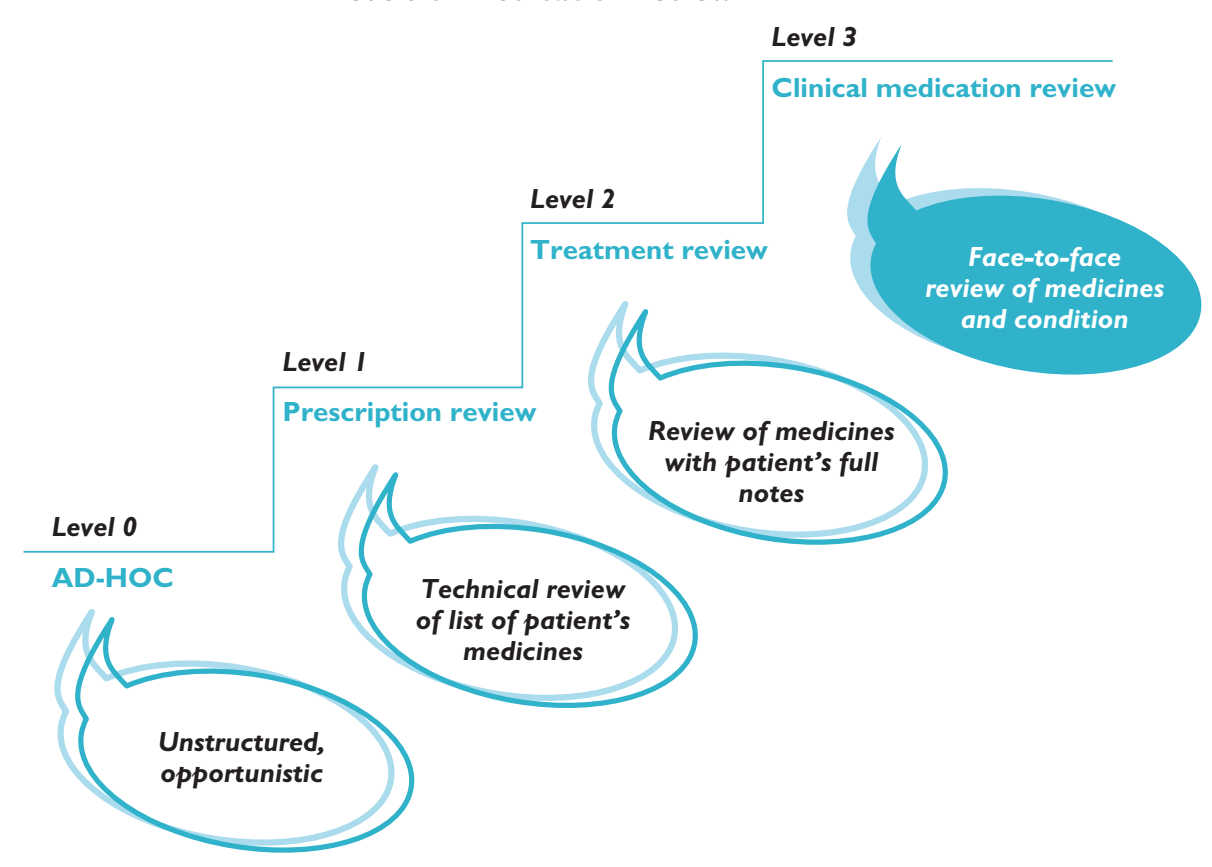

\section{Figure 1}

Different levels of medication review (reproduced with the permission of the authors) [6]

accurate list of the current medication use of a patient across healthcare settings' [7]. In 2002, the Medicines Partnership defined four levels of medication review [6] (Figure 1). An ad hoc review (level 0 ) consists of an isolated question to a patient. A prescription review (level 1) is a review of a patient's medicine by a pharmacist. A treatment review (level 2) requires cooperation between pharmacist and GP (or medical specialist) to review a patient's medicines with the patient's full notes. Finally, a clinical medication review (CMR; level 3) requires face-toface cooperation between pharmacist and/or GP and the patient in order to review a patient's medicines and conditions. When performing a higher level of medication review, cooperation must increase. In 2008, the four levels were reviewed and redefined to three types in order to focus on the purpose of medication review [8]. One important reason was that medicines use review (MUR), a new development in medication review services, did not fit within the previously defined levels of medication review. A MUR is conducted with the patient (level 3 ) but without access to the patient's full notes (level 2). In this new classification, prescription review (type 1), concordance and compliance review (type 2) and clinical medication review (type 3) are defined (Table 1) [8]. However, we believe not all different kinds of medication review are covered within these new defined types of medication reviews, e.g. the former level 2, treatment review, where a pharmacist cooperates with a GP to review the patient's medicines with the patient's full notes. Several classifications of medication review activities are being used but none covers all different activities. One similarity is that both the highest level and/or type of medication review requires the patient's presence. We therefore decided to focus on the participation of the patient.

So far, there are no systematic reviews available that compare the different types of cooperation between family doctors and pharmacists and their impact on patient outcomes. This article systematically reviews the literature on the impact of collaboration between pharmacists and GPs and describes their outcomes on patients' health.

\section{Methods}

A systematic literature search was performed in the databases PubMed and Embase (period until 16 June 2011) with keywords described in Table 2. Abstracts and articles were reviewed by two authors independently (M.M.E.G and J.J.deG.). Articles were first reviewed based on title and abstract $(n=1041)$ and second on full text $(n=152)$. Only English and Dutch written articles were included. Full-text articles were excluded based on language $(n=2)$, lack of cooperation $(n=11)$, lack of patient outcomes $(n=41)$, short communication, e.g. letter, summary or abstract $(n=$ $15)$, and duplicate articles $(n=7)$. Finally, seven additional 


\section{Table 1}

Characteristics of types of medication reviews [8]

\begin{tabular}{|c|c|c|c|c|c|c|}
\hline & Purpose & $\begin{array}{l}\text { Patient's } \\
\text { presence }\end{array}$ & $\begin{array}{l}\text { Access to } \\
\text { patient's } \\
\text { notes }\end{array}$ & $\begin{array}{l}\text { All prescription } \\
\text { medicines }\end{array}$ & $\begin{array}{l}\text { Prescription, complementary } \\
\text { and over-the-counter } \\
\text { medicines }\end{array}$ & $\begin{array}{l}\text { Review of } \\
\text { medicines and/or } \\
\text { condition }\end{array}$ \\
\hline Type 1: prescription review & $\begin{array}{l}\text { Address technical issues relating to } \\
\text { prescription }\end{array}$ & No & Possibly & Possibly & No & Medicines \\
\hline $\begin{array}{l}\text { Type 2: concordance and } \\
\text { compliance review }\end{array}$ & $\begin{array}{l}\text { Address issues relating to patient's } \\
\text { medicine-taking behaviour }\end{array}$ & Usually & Possibly & Yes & Yes & Medicines use \\
\hline $\begin{array}{l}\text { Type 3: clinical medication } \\
\text { review }\end{array}$ & $\begin{array}{l}\text { Address issues relating to the } \\
\text { patient's use of medicines in the } \\
\text { context of their clinical condition }\end{array}$ & Yes & Yes & Yes & Yes & Medicines and condition \\
\hline
\end{tabular}

\section{Table 2}

Keywords used for literature search

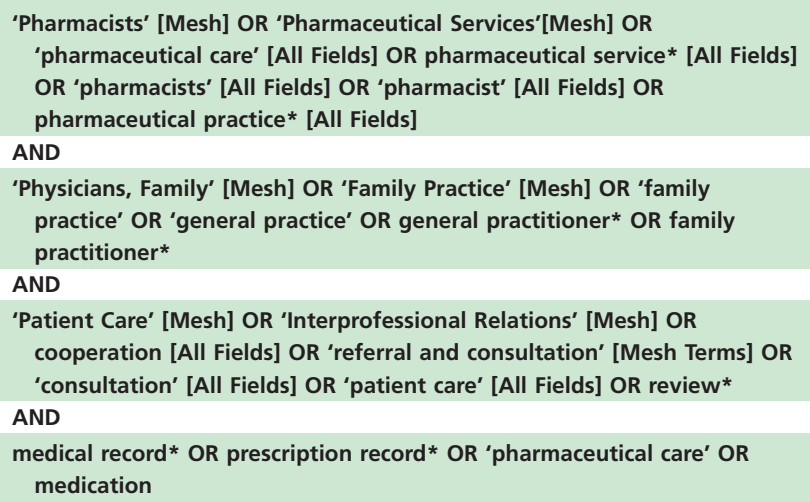

'Pharmacists' [Mesh] OR 'Pharmaceutical Services'[Mesh] OR 'pharmaceutical care' [All Fields] OR pharmaceutical service* [All Fields] OR 'pharmacists' [All Fields] OR 'pharmacist' [All Fields] OR pharmaceutical practice* [All Fields]

AND

'Physicians, Family' [Mesh] OR 'Family Practice' [Mesh] OR 'family practice' OR 'general practice' OR general practitioner* OR family practitioner*

AND

'Patient Care' [Mesh] OR 'Interprofessional Relations' [Mesh] OR cooperation [All Fields] OR 'referral and consultation' [Mesh Terms] OR 'consultation' [All Fields] OR 'patient care' [All Fields] OR review* AND

medical record* OR prescription record* OR 'pharmaceutical care' OR medication

*used to search multiple options at the same time (singular vs. plural).

articles were included, five from references from other articles and two that were not available in the databases at time of the literature search. In total, 83 articles were included (Figure 2). The measure of agreement between the two reviewers, defined as Cohen's kappa ( $\kappa)$, was calculated using SPSS 18.0.3.

\section{Results}

The two authors, who reviewed the titles and abstracts, reached strong agreement $(\kappa=0.766)$. All included articles after review of full text $(n=83)$ are presented in Table 3 according to the following variables: (i) reference; (ii) design and setting of the study; (iii) inclusion criteria for patients; (iv) description of the intervention; (v) whether a patient interview was performed to involve patients' experiences with their medicine-taking behaviour; (vi) outcome; (vii) whether healthcare professionals received additional training; and (viii) whether healthcare profes- sionals received financial reimbursement. Articles are arranged in alphabetical order.

The 83 included articles describe results from 77 studies. Most studies were performed in Europe $(n=40)$, followed by the USA/Canada $(n=19)$ and Australia/New Zealand $(n=18)$. A majority of studies $(n=60)$ describe patient involvement using a patient interview or consultation (either at home or at the pharmacy/GP practice). About one-third of the studies (26 of 77 ) provided information on additional training, mostly for participating pharmacists. Only 11 studies reported financial reimbursement for participating healthcare providers. The amounts differed and were not always mentioned.

Studies with a high level of evidence, such as randomized controlled trials, showed more significant results when compared with studies having a lower level of evidence, such as retrospective observational studies. Not all studies were able to conclude with hard outcomes, such as decrease in hospital admissions or costs. Only nine studies reported outcomes on hospital admissions. When we focused more on these studies, we found some differences. Farris et al. [9] showed a nonsignificant decrease in hospital admissions. A single-group pre-post design was used, and 199 patients were included (no power calculation was performed). Each primary healthcare team (PHCT) received training, but team pharmacists were generally not patients' dispensing pharmacists. An average of 3.9 issues were defined per patient, and an average of $59 \%$ of issues were resolved. However, these numbers showed large differences between the six PHCTs. Six studies used a randomized controlled trial (RCT) design. Graffen et al. [10] showed no differences in hospitalization rates among 402 included patients (determined by power calculation). No additional training was provided and no patient interview performed. Hospitalizations were determined by asking patients. Holland et al. [11] found a statistically significant increase in hospital admissions. A total of 872 patients were included (determined by power calculation). Pharmacists received a 2 day training course. Leendertse [12] found a nonsignificant decrease in medication-related 


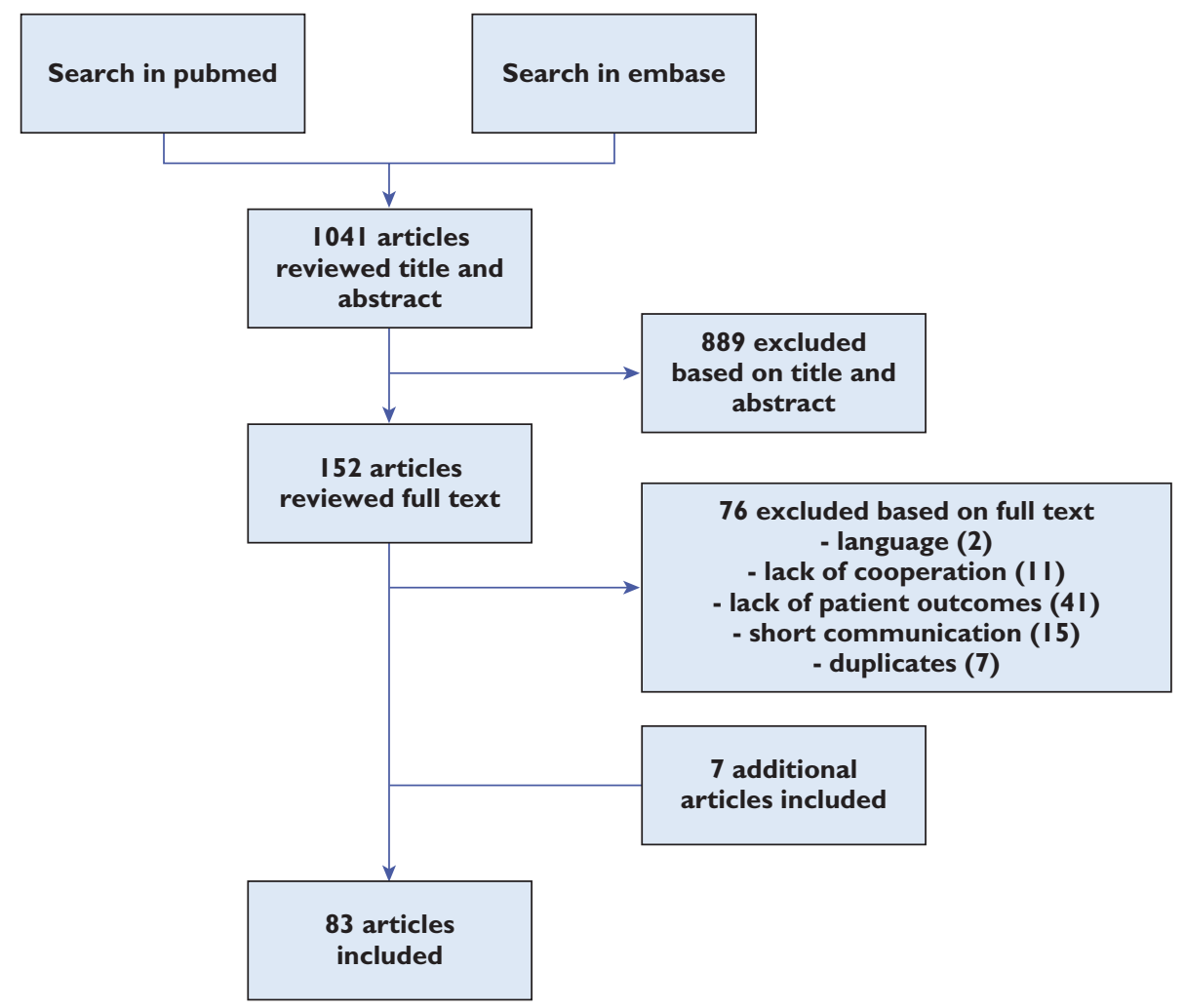

Figure 2

Article selection

hospital admissions; however, the intervention did show a statistically significant result for patients with five or more diseases. In this RCT, 674 patients were included (aim 14200 based on power calculation). Pharmacists received additional training. Lenaghan et al. [13] found no differences in hospital admissions among 136 included patients (aim 164 based on power calculation). Pharmacists did not receive additional training but were experienced in performing home medicines reviews (HMRs). Makowsky et al. [14] found a statistically significant decrease in hospital admissions after 3 but not after 6 months. A total of 452 patients were included (aim 650 based on power calculation). The intervention was performed by experienced pharmacists who did not receive additional training. Nazareth et al. [15] found no differences in hospital admissions among 362 included patients (aim 390 based on power calculation). No additional training was provided for participating healthcare providers. Two cohort studies performed by Roughead et al. [16, 17] showed a statistically significant decrease in hospitalization rates for specific patient groups. Their first study included 273 patients exposed to an HMR and showed a $45 \%$ reduction in hospitalization for heart failure patients [16]. Their second study included 816 patients exposed to an HMR and showed $79 \%$ reduction in hospitalization for warfarin- associated bleeding [17]. Both studies were performed by experienced pharmacists, and no additional training was provided.

Other significant results found were decreases in number of drug-related problems, improved prescribing of medication, improved quality of life scores, improved medication appropriateness index scores, increased compliance and patient knowledge, and improved clinical values, e.g. cholesterol levels. Most studies described positive outcomes on satisfaction. Healthcare providers and patients were satisfied when they were involved in projects. Studies also showed that when cooperation between healthcare providers and patients occurred, more drug-related problems were defined and solved.

\section{Discussion}

A recent Cochrane review focused on health-related outcomes of clinical pharmacy services [18]. Pharmacist interventions resulted in improvement in most clinical outcomes, but these were not always statistically significant. The Cochrane review only describes pharmacist interventions, whereas our review focuses on interventions with cooperation between pharmacists and GPs. 


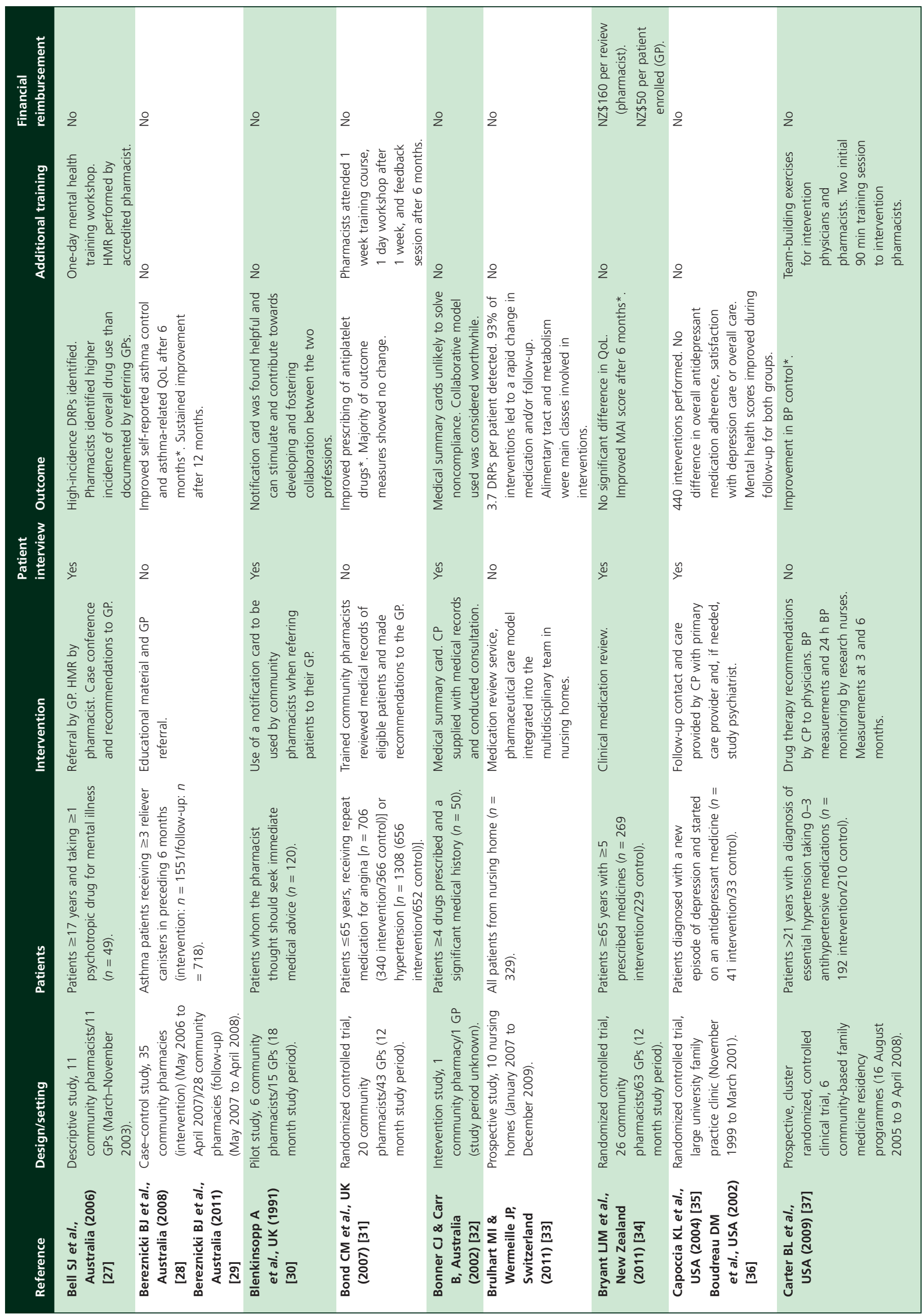




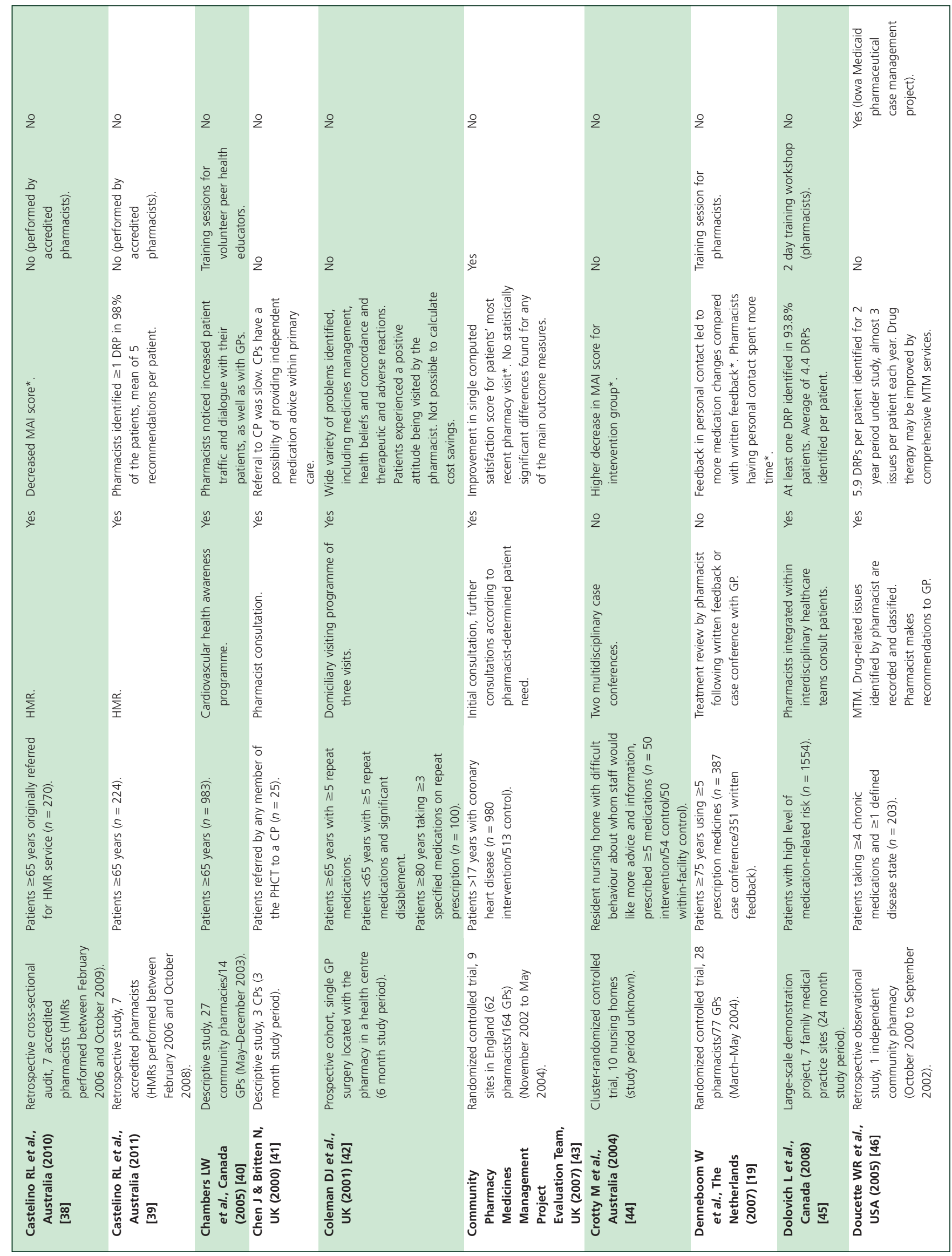


BJCP M.M. E. Geurts et al.

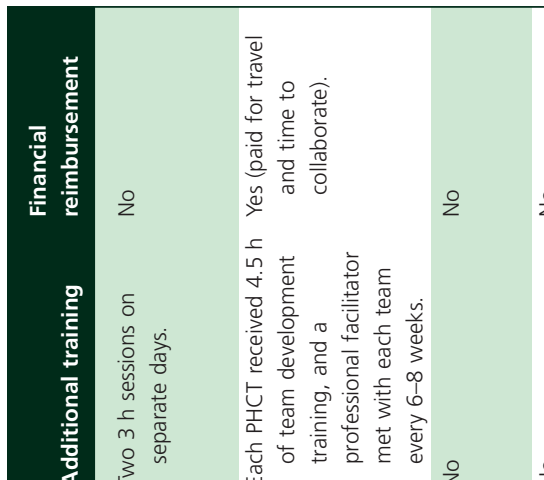

密
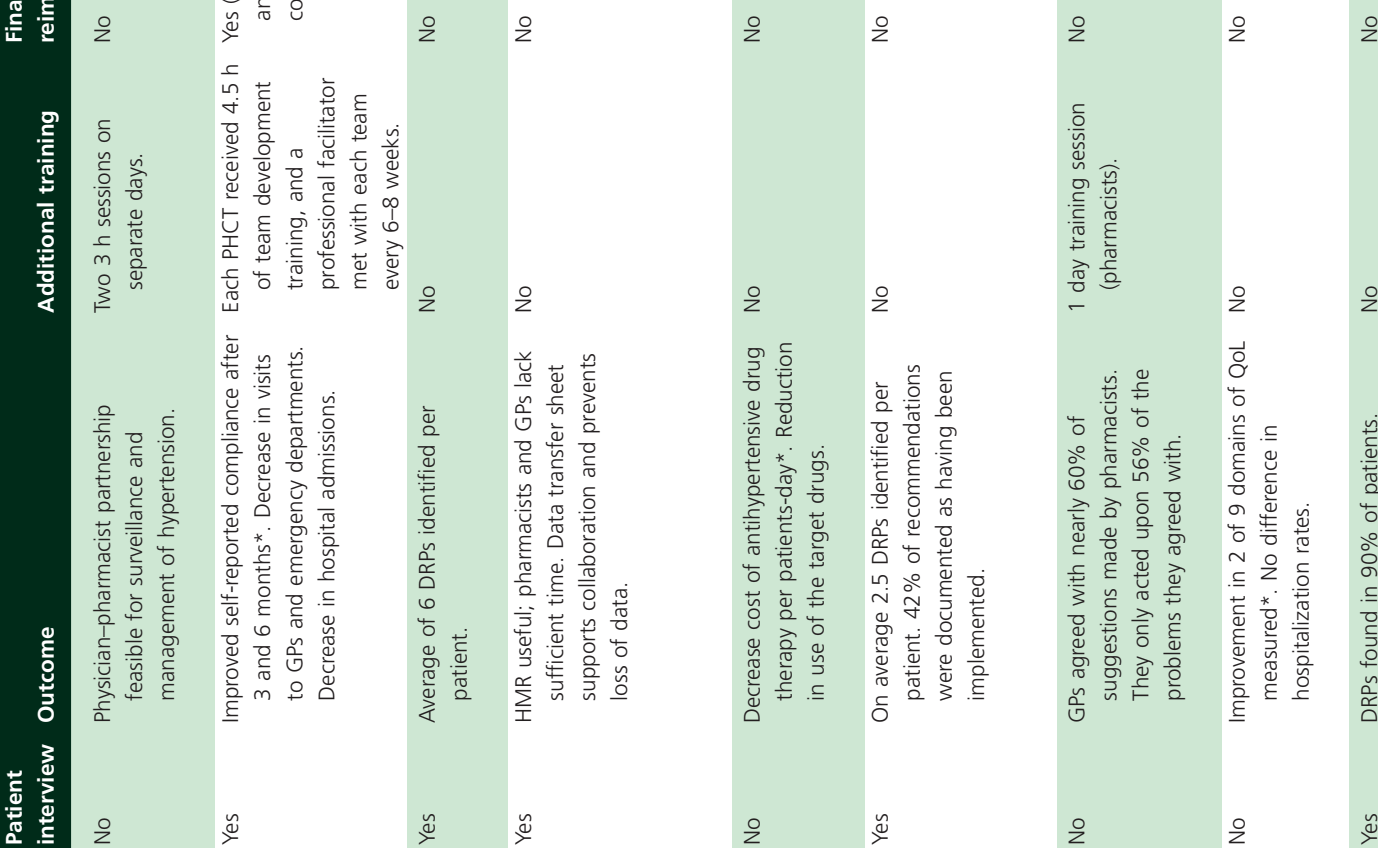

$\stackrel{2}{2}$

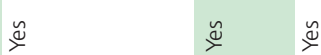
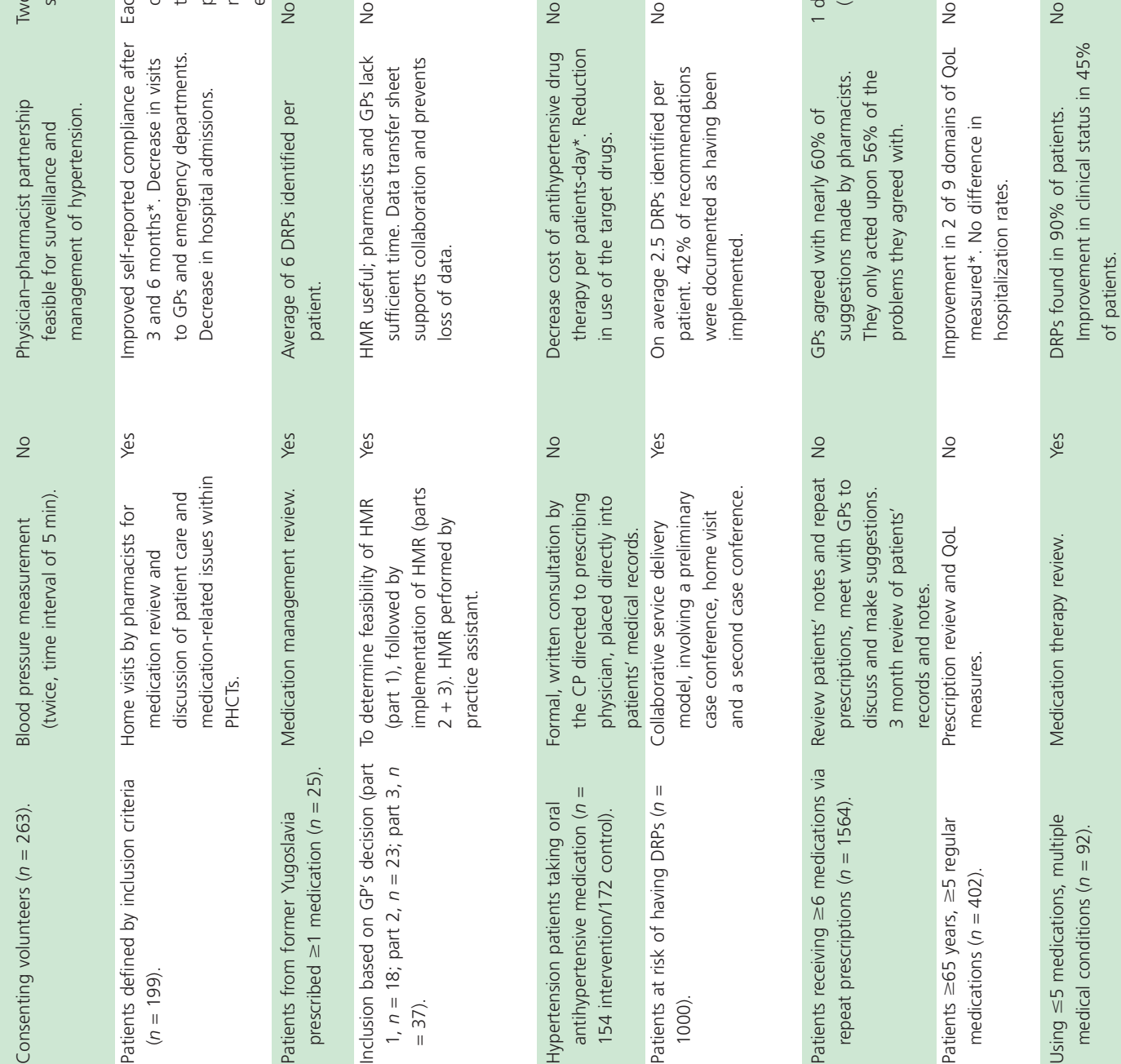

일
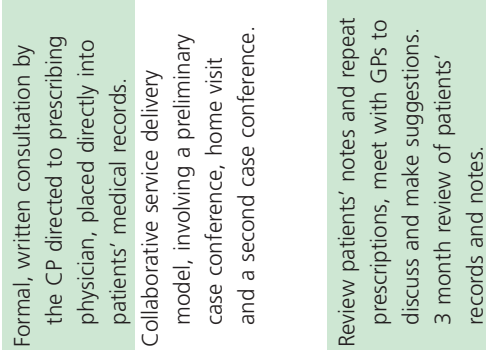

웅

ญั้

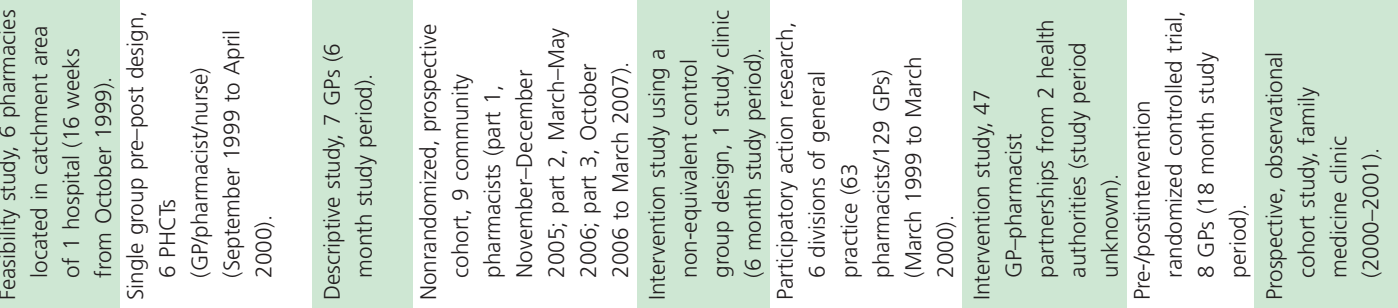

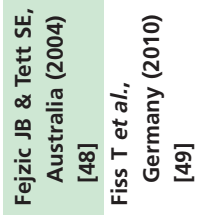

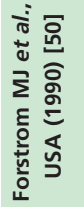

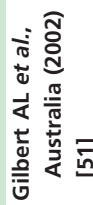

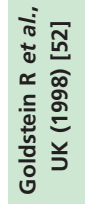

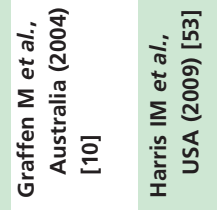




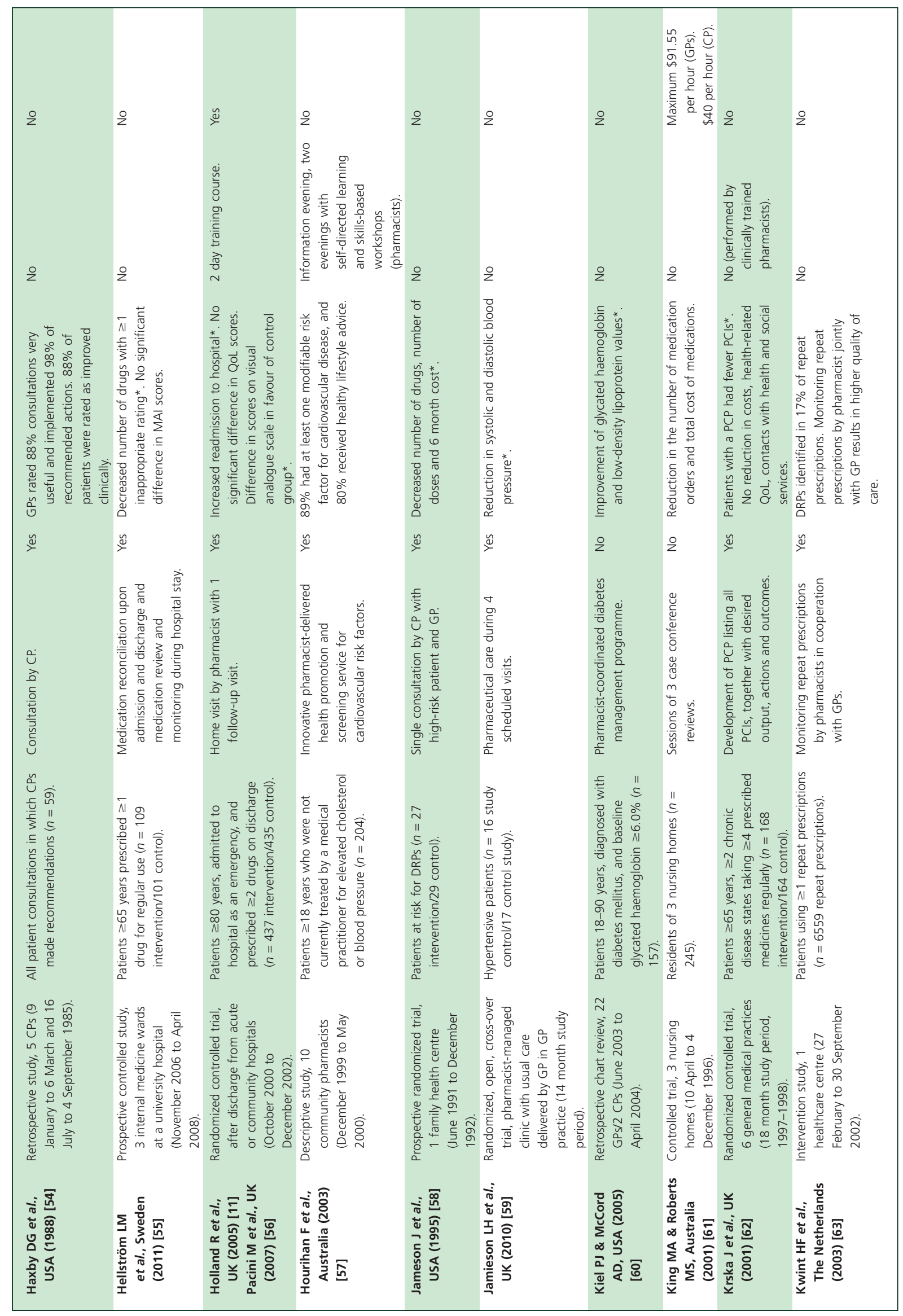




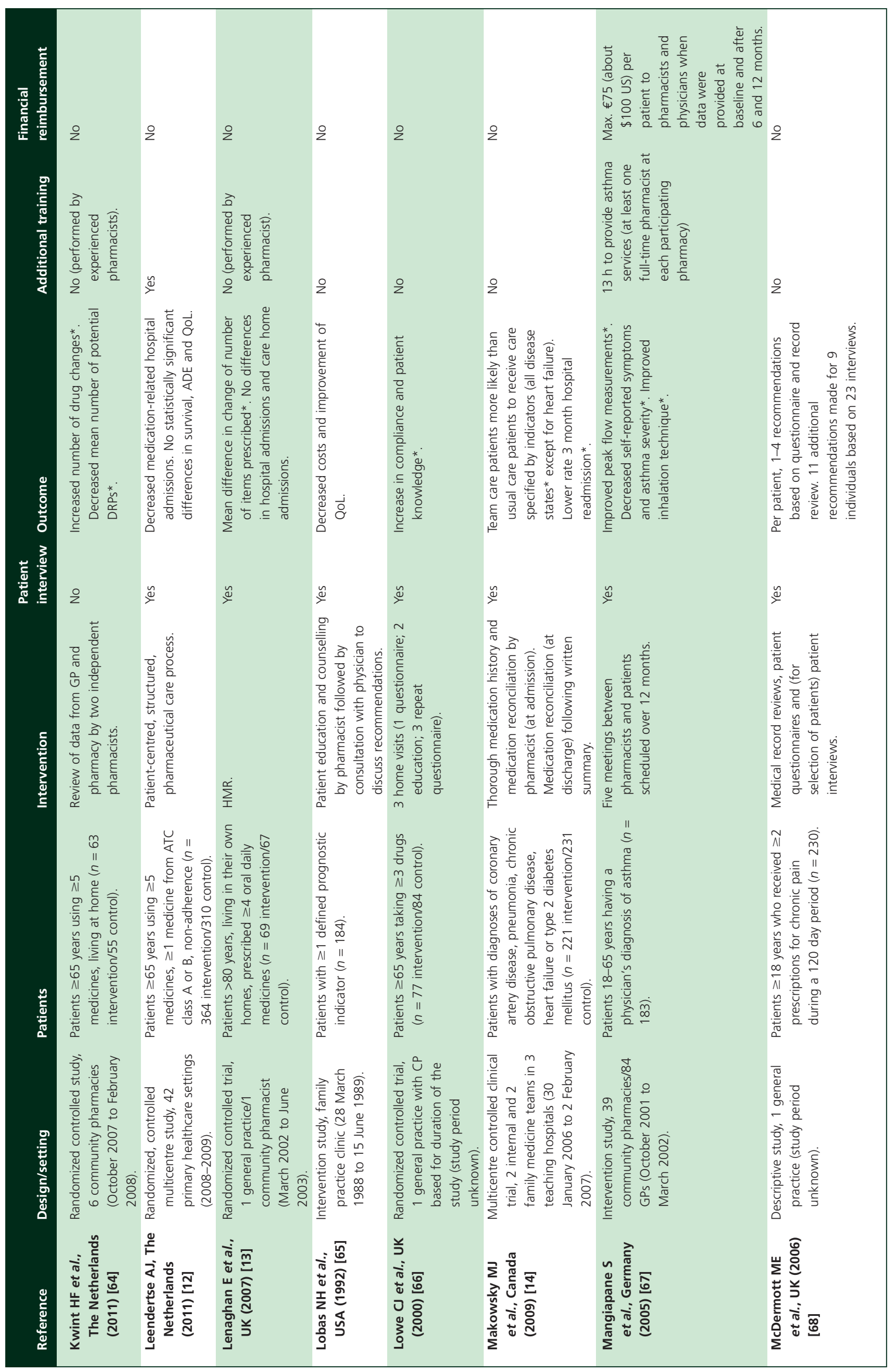




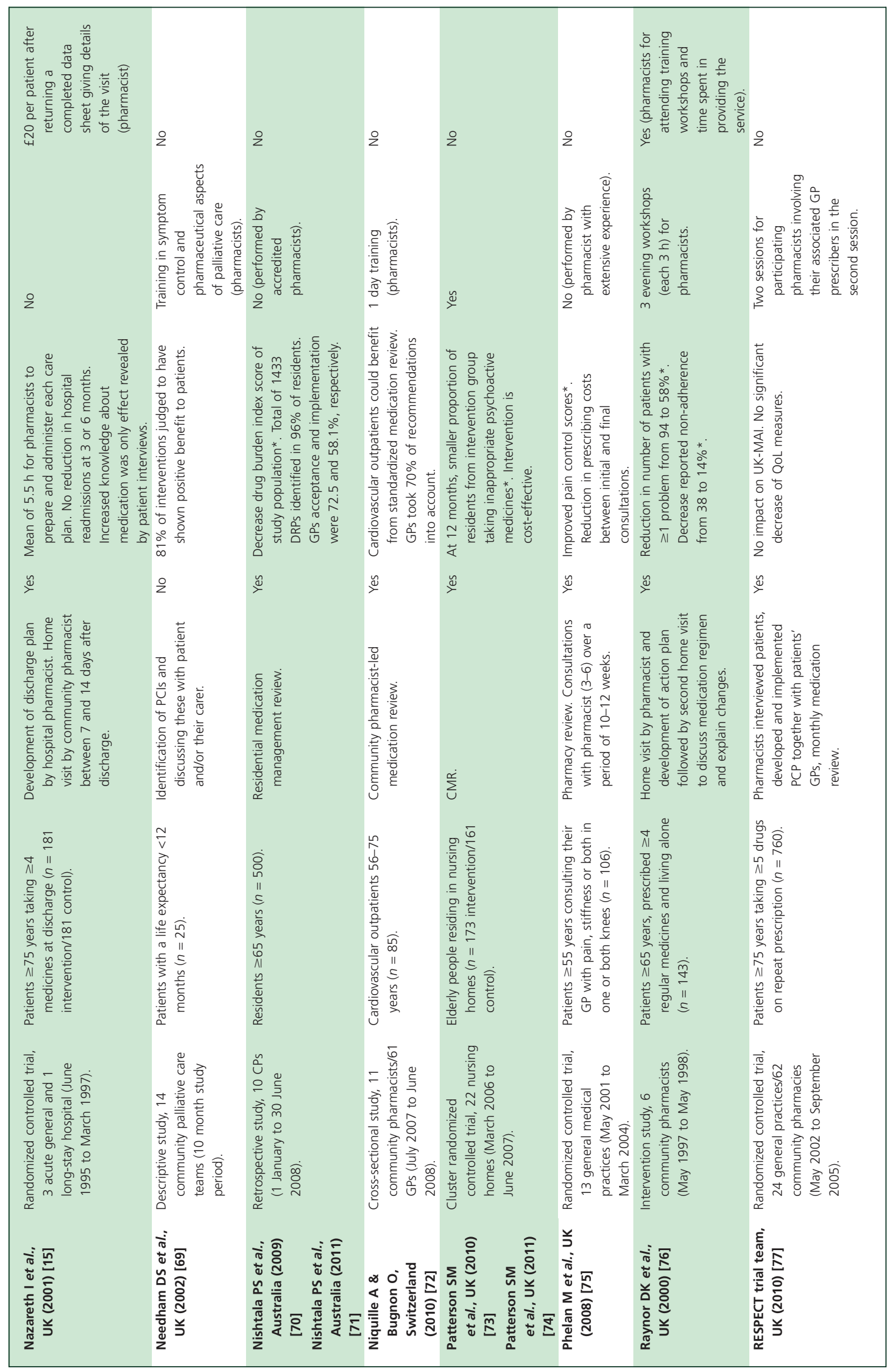




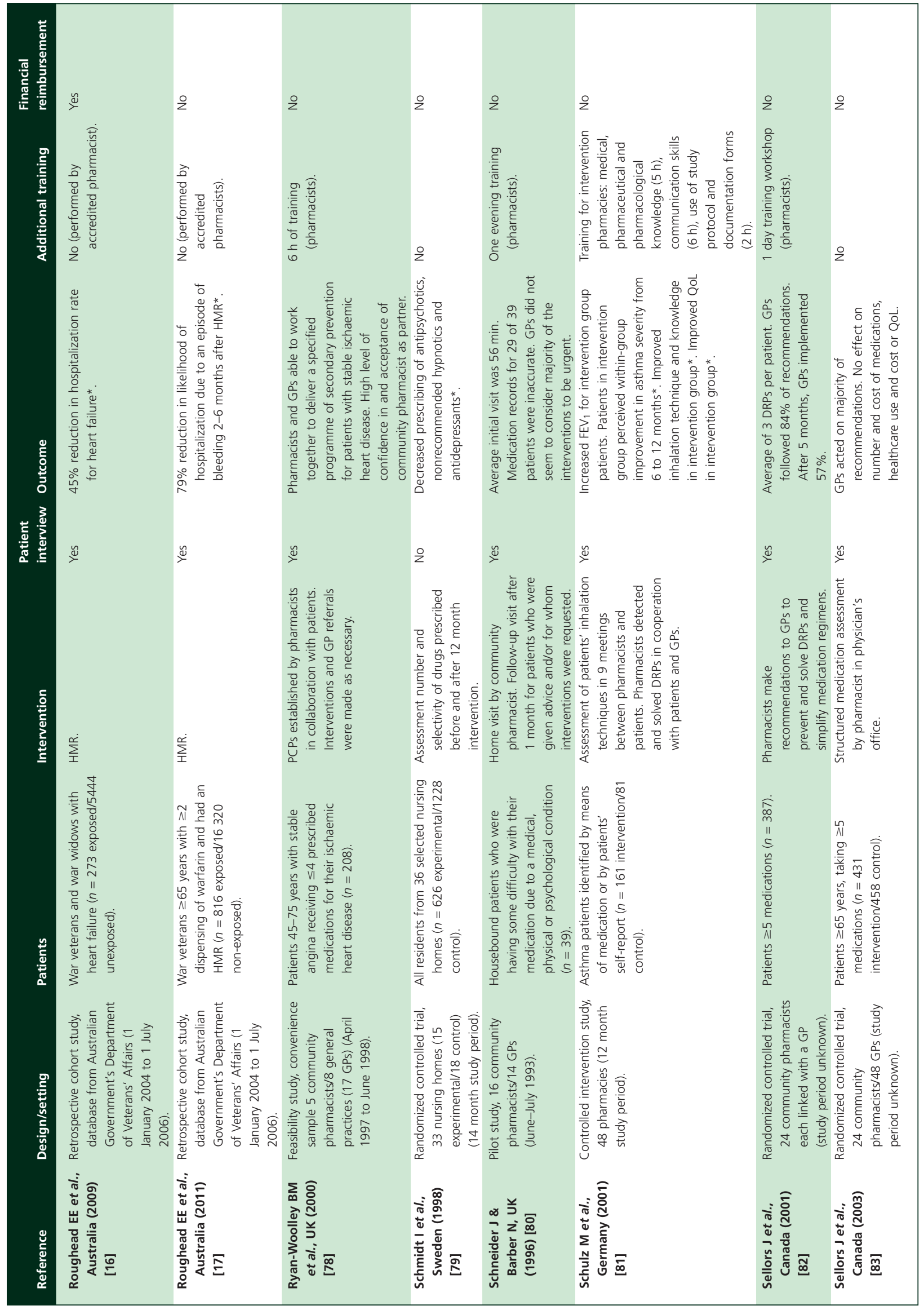




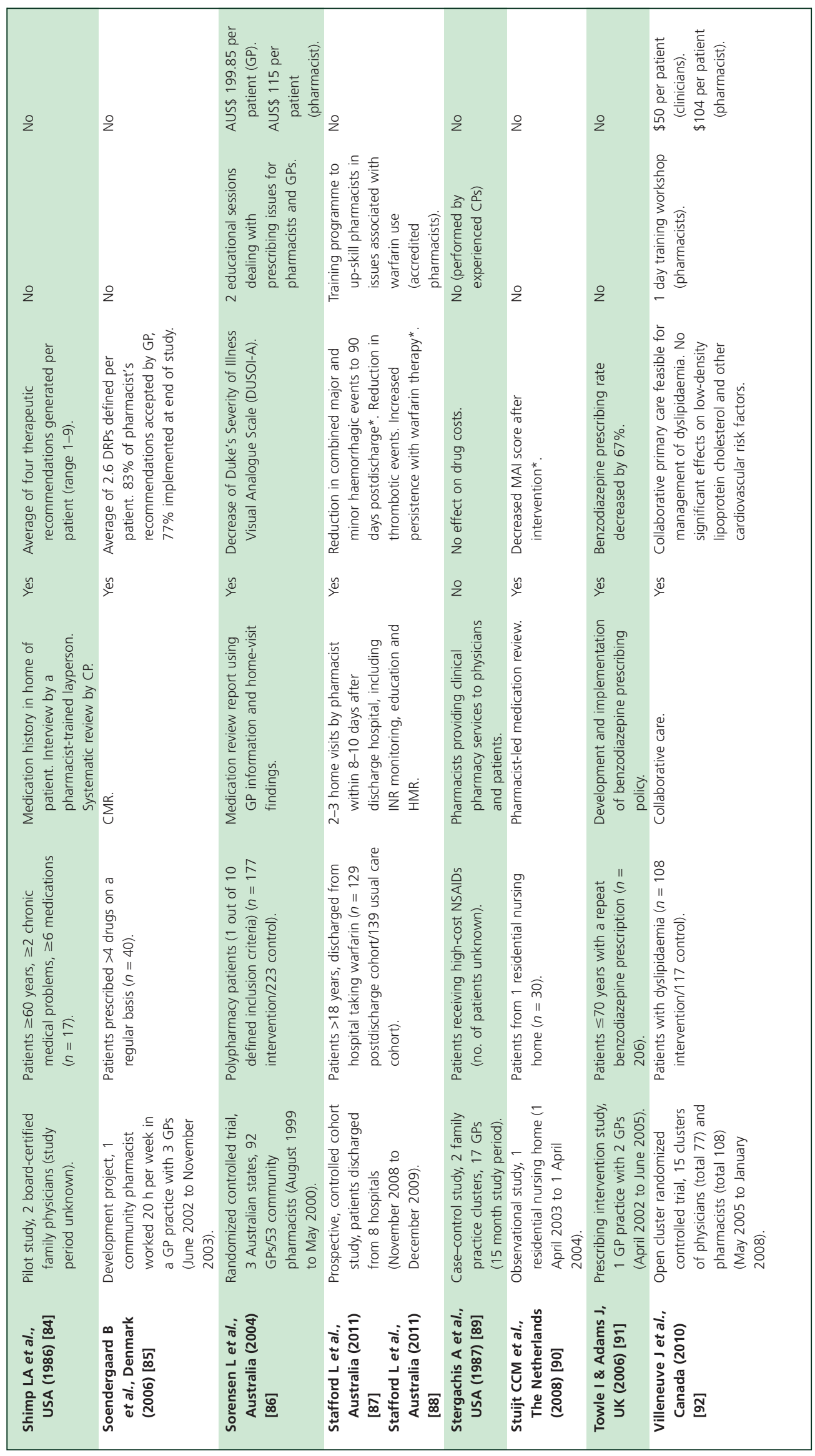



Only nine studies report hard outcomes, such as hospital (re)admissions [9-17]. Three studies show a significant decrease in hospital (re)admissions [14, 16, 17], and one study shows an increase in hospital admissions [11]. The intervention described by Holland et al. is performed by a review pharmacist [11]. Also, the intervention by Farris et al. [9] was not performed by the patients' own pharmacist, whereas the other seven studies did include cooperation between the patients' own pharmacist and GP. All studies with no differences in hospital admissions provided no additional training to pharmacists $[10,13,15]$; however, one study did mention that the intervention was performed by experienced pharmacists [13]. Graffen et al. [10] determined hospitalization rates by asking patients, which could result in recall bias. Other studies did provide additional training to pharmacists or mentioned that pharmacists were experienced. This could mean that the pharmacists involved in the selected studies were not able to perform an adequate medication review or medication reconciliation without additional training. Not all studies managed to include sufficient patient numbers necessary according to their power calculation. Two studies did report a decrease in hospital admissions, which could be significant after including higher patient numbers $[12,14]$ A subanalysis from Leendertse et al. [12] did show a significant decrease in medication-related hospital admissions for patients with $\geq 5$ diseases. In order to retrieve hard outcomes, such as hospital (re)admissions, randomized clinical trials with large numbers of patients are needed. In most studies, numbers are too small to be able to study hard outcomes. Also, the level of cooperation and communication between healthcare providers is important. Denneboom et al. [19] performed a study using level 2 medication review and concluded that feedback in personal contact led to significantly more medication changes when compared with written feedback. When there is personal contact, healthcare providers can motivate their opinion on possible medication changes and, together, might choose a different intervention than they originally had suggested instead of rejecting the proposed intervention outright. When the patient is also involved, the intervention will have a higher chance of long-term success. When patients agree with the proposed intervention, they will be more motivated to change [4, 20-22]. The quality of collaboration is also important. Isetts et al. [23] performed a quality assessment of therapeutic determinations made by pharmacists. Decisions made by healthcare providers were found to be clinically credible based on the evaluations and comments of a peer review panel. When pharmaceutical care practitioners collaborate with physicians to provide drug therapy management services, this may help to reduce drug-related morbidity and improve therapeutic outcomes. Several classifications of medication review activities are used, but none of the classification systems is able to cover all different kinds of activities. In order to compare different activities, it is important to develop one classification system that can be used for all different activities performed throughout the whole world.

Most studies performed focused on elderly patients with multiple morbidities using multiple medicines (polypharmacy). These patients are at higher risk of complications and would benefit most from a periodic CMR $[24,25]$. In many countries, clinical pharmacologists are also involved in CMRs; these studies were not included in this review, because the focus is on pharmacists and GPs as healthcare providers, with whom patients have a relationship.

Besides study design and patient outcomes, we looked at additional training for healthcare providers and financial reimbursement. Performing services such as medication review or medication reconciliation takes time. When performed at a higher level, time investment will increase. We question whether all healthcare providers have sufficient skill and experience to perform these services, knowing it involves complex patients with multiple morbidities and polypharmacy. In about one-third of the included studies, additional training was provided to participating healthcare providers, usually for pharmacists. This training usually concerned education about specific diseases and communication skills. Twelve studies mention that they did not provide additional training, but the studies were performed by accredited and experienced (clinical) pharmacists. Of these studies, six were performed in Australia, where the service called home medicines review (HMR) can only be performed by accredited pharmacists who are reimbursed for their services. Australia is well known for the development and implementation of HMRs.

Some studies focused on cost-effectiveness of medication review services, but none could show significant results. A recent study by Perez et al. [26] showed economic evaluations of clinical pharmacy services from 2001 to 2005. A median benefit-to-cost ratio of 4.81:1 was found, meaning that for every $\$ 1$ spent a $\$ 4.81$ reduction in costs or other economic benefits was achieved. When other healthcare providers besides pharmacists, e.g. GPs, are involved, costs of the intervention will increase without knowing what this means for the achieved benefits. More research on cost-effectiveness of multidisciplinary interventions is necessary.

The strength of this article is its use of a systematic literature search. However, we did find five relevant articles outside the performed search, which may mean we missed other articles. One reason for this could be that certain articles do not have well-defined keywords or that cooperation is not explicitly mentioned in the title or abstract. We excluded two articles based on their language (Norwegian and French). We do not believe this influenced our results.

We recommend that future research should include a large randomized clinical trial with high patient numbers focused on hard outcomes, e.g. hospital (re)admissions and 
cost-effectiveness. With such a study, healthcare providers would be able to show their professional skills and how they can provide benefit to patients at high risk. This will make it easier to determine the necessary additional skills and proper reimbursement for time spent.

\section{Conclusions}

Many different interventions are described where pharmacists and GPs work together to improve patients' health. Besides results on patient satisfaction, drug-related problems, quality of life and clinical values, fewer studies report hard outcomes, and results are not all comparable. Randomized controlled trials should be able to describe hard outcomes, but large patient groups will be needed to perform such studies. Patient involvement is important for motivation to change and for a long-term effect of the proposed intervention.

\section{Competing Interests}

There are no competing interests to declare.

We thank Truus van Ittersum, library services of Research Institute SHARE, for her help with the systematic literature search. We thank Timothy Broesamle for editing this article.

\section{REFERENCES}

1 FIP Working Group on Collaborative Practice. FIP Reference Paper Collaborative Practice. 2009. Available at http://www. fip.org/www/uploads/database_file.php?id=319\&table_id= (last accessed 12 October 2011).

2 Gillespie U, Alassaad A, Henrohn D, Garmo H, Hammarlund-Udenaes $\mathrm{M}$, Toss $\mathrm{H}$ et al. A comprehensive pharmacist intervention to reduce morbidity in patients 80 years or older: a randomized controlled trial. Arch Intern Med 2009; 169: 894-900.

3 Michie S, Miles J, Weinman J. Patient-centredness in chronic illness: what is it and does it matter? Patient Educ Couns 2003; 51: 197-206.

4 Holman $\mathrm{H}$, Lorig K. Patients as partners in managing chronic disease. Partnership is a prerequisite for effective and efficient health care. BMJ 2000; 320: 526-7.

5 Cipolle RJ, Strand LM, Morley PC. In: Pharmaceutical Care Practice The Clinician's Guide, 2nd edn. New York, NY: The McGraw-Hill Companies, Inc., 2004.

6 Task Force on Medicines Partnership and The National Collaborative Medicines Management, Services Programme. Room for Review: A guide to medication review: the agenda for patients, practitioners and managers. 2002. Available at http://www.npc.nhs.uk/review_medicines/intro/resources/ room_for_review.pdf (last accessed 12 October 2011).
7 Karapinar-Carkit F, Borgsteede SD, Zoer J, Smit HJ, Egberts AC, van den Bemt PM. Effect of medication reconciliation with and without patient counseling on the number of pharmaceutical interventions among patients discharged from the hospital. Ann Pharmacother 2009; 43: 1001-10.

8 Medicines PP. A Guide to Medication Review 2008. 2008. Available at http://www.npc.co.uk/review_medicines/ intro/resources/agtmr_web1.pdf (last 12 accessed October 2011).

9 Farris KB, Cote I, Feeny D, Johnson JA, Tsuyuki RT, Brilliant S et al. Enhancing primary care for complex patients. Demonstration project using multidisciplinary teams. Can Fam Physician 2004; 50: 998-1003.

10 Graffen M, Kennedy D, Simpson M. Quality use of medicines in the rural ambulant elderly: a pilot study. Rural Remote Health 2004; 4: 184.

11 Holland R, Lenaghan E, Harvey I, Smith R, Shepstone L, Lipp A et al. Does home based medication review keep older people out of hospital? The HOMER randomised controlled trial. BMJ 2005; 330: 293.

12 Leendertse AJ. Hospital Admissions Related to Medication. Prevalence, Provocation and Prevention. Utrecht: Utrecht University, 2010.

13 Lenaghan E, Holland R, Brooks A. Home-based medication review in a high risk elderly population in primary care - the POLYMED randomised controlled trial. Age Ageing 2007; 36 : 292-7.

14 Makowsky MJ, Koshman SL, Midodzi WK, Tsuyuki RT. Capturing outcomes of clinical activities performed by a rounding pharmacist practicing in a team environment: the COLLABORATE study [NCT00351676]. Med Care 2009; 47: 642-50.

15 Nazareth I, Burton A, Shulman S, Smith P, Haines A, Timberal H. A pharmacy discharge plan for hospitalized elderly patients - a randomized controlled trial. Age Ageing 2001; 30: 33-40.

16 Roughead EE, Barratt JD, Ramsay E, Pratt N, Ryan P, Peck R et al. The effectiveness of collaborative medicine reviews in delaying time to next hospitalization for patients with heart failure in the practice setting: results of a cohort study. Circ Heart Fail 2009; 2: 424-8.

17 Roughead EE, Barratt JD, Ramsay E, Pratt N, Ryan P, Peck R et al. Collaborative home medicines review delays time to next hospitalization for warfarin associated bleeding in Australian war veterans. J Clin Pharm Ther 2011; 36: 27-32.

18 Nkansah N, Mostovetsky O, Yu C, Chheng T, Beney J, Bond CM et al. Effect of outpatient pharmacists' non-dispensing roles on patient outcomes and prescribing patterns. Cochrane Database Syst Rev 2010; (7): CD000336.

19 Denneboom W, Dautzenberg MG, Grol R, De Smet PA. Treatment reviews of older people on polypharmacy in primary care: cluster controlled trial comparing two approaches. Br J Gen Pract 2007; 57: 723-31.

20 Charles C, Whelan T, Gafni A. What do we mean by partnership in making decisions about treatment? BMJ 1999; 319: 780-2. 
21 Jordan JL, Ellis SJ, Chambers R. Defining shared decision making and concordance: are they one and the same? Postgrad Med J 2002; 78: 383-4.

22 Osterberg L, Blaschke T. Adherence to medication. N Engl J Med 2005; 353: 487-97.

23 Isetts BJ, Brown LM, Schondelmeyer SW, Lenarz LA. Quality assessment of a collaborative approach for decreasing drug-related morbidity and achieving therapeutic goals. Arch Intern Med 2003; 163: 1813-20.

24 Warlé-van Herwaarden M, Kramers C, Sturkenboom M, Van den Bemt PMLA, De Smet PAGM. Targeting outpatient drug safety: recommendations of the Dutch HARM-Wrestling task force. 2011. Available at http://www.knmp.nl/ downloads/medicijnen-zorgverlening/medicatieveiligheid/ harmwrestlingEnglishcopyrightKNMP.pdf (last accessed 12 October 2011).

25 De Smet PA. Hospital admissions related to medications and implementing guidelines. Arch Intern Med 2009; 169: 810-1.

26 Perez A, Doloresco F, Hoffman JM, Meek PD, Touchette DR, Vermeulen LC et al. ACCP: economic evaluations of clinical pharmacy services: 2001-2005. Pharmacotherapy 2008; 28 : 285 e-323e.

27 Bell JS, Whitehead P, Aslani P, McLachlan AJ, Chen TF. Drug-related problems in the community setting: pharmacists' findings and recommendations for people with mental illnesses. Clin Drug Investig 2006; 26: 415-25.

28 Bereznicki BJ, Peterson GM, Jackson SL, Walters H, Fitzmaurice K, Gee P. Pharmacist-initiated general practitioner referral of patients with suboptimal asthma management. Pharm World Sci 2008; 30: 869-75.

29 Bereznicki B, Peterson G, Jackson S, Walters EH, Gee P. The sustainability of a community pharmacy intervention to improve the quality use of asthma medication. J Clin Pharm Ther 2011; 36: 144-51.

30 Blenkinsopp A, Jepson M, Drury M. Using a notification card to improve communication between community pharmacists and general practitioners. Br J Gen Pract 1991; 41: 116-8.

31 Bond CM, Fish A, Porteous TH, Reid JP, Scott A, Antonazzo E. $A$ randomised controlled trial of the effects of note-based medication review by community pharmacists on prescribing of cardiovascular drugs in general practice. Int J Pharm Pract 2007; 15: 39-46.

32 Bonner CJ, Carr B. Medication compliance problems in general practice: detection and intervention by pharmacists and doctors. Aust J Rural Health 2002; 10:33-8.

33 Brulhart MI, Wermeille JP. Multidisciplinary medication review: evaluation of a pharmaceutical care model for nursing homes. Int J Clin Pharm 2011; 33: 549-57.

34 Bryant LJM, Coster G, Gamble GD, McCormick RN. The General Practitioner-Pharmacist Collaboration (GPPC) study: a randomised controlled trial of clinical medication reviews in community pharmacy. Int J Pharm Pract 2011; 19: 94-105.

35 Capoccia KL, Boudreau DM, Blough DK, Ellsworth AJ, Clark DR, Stevens NG et al. Randomized trial of pharmacist interventions to improve depression care and outcomes in primary care. Am J Health Syst Pharm 2004; 61: 364-72.

36 Boudreau DM, Capoccia KL, Sullivan SD, Blough DK, Ellsworth AJ, Clark DL et al. Collaborative care model to improve outcomes in major depression. Ann Pharmacother 2002; 36: 585-91.

37 Carter BL, Ardery G, Dawson JD, James PA, Bergus GR, Doucette WR et al. Physician and pharmacist collaboration to improve blood pressure control. Arch Intern Med 2009; 169: 1996-2002.

38 Castelino RL, Bajorek BV, Chen TF. Retrospective evaluation of home medicines review by pharmacists in older Australian patients using the medication appropriateness index. Ann Pharmacother 2010; 44: 1922-9.

39 Castelino RL, Bajorek BV, Chen TF. Are interventions recommended by pharmacists during Home Medicines Review evidence-based? J Eval Clin Pract 2011; 17: 104-10.

40 Chambers LW, Kaczorowski J, Dolovich L, Karwalajtys T, Hall HL, McDonough B et al. A community-based program for cardiovascular health awareness. Can J Public Health 2005; 96: 294-8.

41 Chen J, Britten N. 'Strong medicine': an analysis of pharmacist consultations in primary care. Fam Pract 2000; 17: 480-3.

42 Coleman DJ, Portlock J, Brown D. Delivering domiciliary pharmaceutical care from a health centre pharmacy. Int J Pharm Pract 2001; 9: 127-37.

43 Community Pharmacy Medicines Management Project Evaluation Team. The MEDMAN study: a randomized controlled trial of community pharmacy-led medicines management for patients with coronary heart disease. Fam Pract 2007; 24: 189-200.

44 Crotty M, Halbert J, Rowett D, Giles L, Birks R, Williams H et al. An outreach geriatric medication advisory service in residential aged care: a randomised controlled trial of case conferencing. Age Ageing 2004; 33: 612-7.

45 Dolovich L, Pottie K, Kaczorowski J, Farrell B, Austin Z, Rodriguez $C$ et al. Integrating family medicine and pharmacy to advance primary care therapeutics. Clin Pharmacol Ther 2008; 83: 913-7.

46 Doucette WR, McDonough RP, Klepser D, McCarthy R. Comprehensive medication therapy management: identifying and resolving drug-related issues in a community pharmacy. Clin Ther 2005; 27: 1104-11.

47 Earle KA, Taylor P, Wyatt S, Burnett S, Ray J. A physician-pharmacist model for the surveillance of blood pressure in the community: a feasibility study. J Hum Hypertens 2001; 15: 529-33.

48 Fejzic JB, Tett SE. Medication management reviews for people from the former Yugoslavia now resident in Australia. Pharm World Sci 2004; 26: 271-6.

49 Fiss T, Ritter CA, Alte D, van den Berg N, Hoffmann W. Detection of drug related problems in an interdisciplinary health care model for rural areas in Germany. Pharm World Sci 2010; 32: 566-74. 
50 Forstrom MJ, Ried LD, Stergachis AS, Corliss DA. Effect of a clinical pharmacist program on the cost of hypertension treatment in an HMO family practice clinic. DICP 1990; 24: 304-9.

51 Gilbert AL, Roughead EE, Beilby J, Mott K, Barratt JD. Collaborative medication management services: improving patient care. Med J Aust 2002; 177: 189-92.

52 Goldstein R, Hulme $H$, Willits J. Reviewing repeat prescribing - general practitioners and community pharmacists working together. Int J Pharm Pract 1998; 6: 60-6.

53 Harris IM, Westberg SM, Frakes MJ, Van Vooren JS. Outcomes of medication therapy review in a family medicine clinic. J Am Pharm Assoc 2009; 49: 623-7.

54 Haxby DG, Weart CW, Goodman BW Jr. Family practice physicians' perceptions of the usefulness of drug therapy recommendations from clinical pharmacists. Am J Hosp Pharm 1988; 45: 824-7.

55 Hellstrom LM, Bondesson A, Hoglund P, Midlov P, Holmdahl L, Rickhag E et al. Impact of the Lund Integrated Medicines Management (LIMM) model on medication appropriateness and drug-related hospital revisits. Eur J Clin Pharmacol 2011; 67: 741-52.

56 Pacini M, Smith RD, Wilson EC, Holland R. Home-based medication review in older people: is it cost effective? Pharmacoeconomics 2007; 25: 171-80.

57 Hourihan F, Krass I, Chen T. Rural community pharmacy: a feasible site for a health promotion and screening service for cardiovascular risk factors. Aust J Rural Health 2003; 11 : 28-35.

58 Jameson J, VanNoord G, Vanderwoud K. The impact of a pharmacotherapy consultation on the cost and outcome of medical therapy. J Fam Pract 1995; 41: 469-72.

59 Jamieson LH, Scally AJ, Chrystyn H. A randomised comparison of practice pharmacist-managed hypertension providing Level 3 Medication Review versus usual care in general practice. J Appl Ther Res 2010; 7: 77-86.

60 Kiel PJ, McCord AD. Pharmacist impact on clinical outcomes in a diabetes disease management program via collaborative practice. Ann Pharmacother 2005; 39: 1828-32.

61 King MA, Roberts MS. Multidisciplinary case conference reviews: improving outcomes for nursing home residents, carers and health professionals. Pharm World Sci 2001; 23: $41-5$.

62 Krska J, Cromarty JA, Arris F, Jamieson D, Hansford D, Duffus PR et al. Pharmacist-led medication review in patients over 65: a randomized, controlled trial in primary care. Age Ageing 2001; 30: 205-11.

63 Kwint HF, Luchtman T, Krijger-Dijkema JM, Eekhof J, De Kanter J. Physician and pharmacist monitor together. Monitoring of repeat prescriptions for drug-related problems. Pharm Weekbl 2003; 138: 1732-7.

64 Kwint HF, Faber A, Gussekloo J, Bouvy ML. Effects of medication review on drug-related problems in patients using automated drug-dispensing systems: a pragmatic randomized controlled study. Drugs Aging 2011; 28: 305-14.
65 Lobas NH, Lepinski PW, Abramowitz PW. Effects of pharmaceutical care on medication cost and quality of patient care in an ambulatory-care clinic. Am J Hosp Pharm 1992; 49: 1681-8.

66 Lowe CJ, Raynor DK, Purvis J, Farrin A, Hudson J. Effects of a medicine review and education programme for older people in general practice. Br J Clin Pharmacol 2000; 50: $172-5$.

67 Mangiapane S, Schulz M, Muhlig S, Ihle P, Schubert I, Waldmann HC. Community pharmacy-based pharmaceutical care for asthma patients. Ann Pharmacother 2005; 39: 1817-22.

68 McDermott ME, Smith BH, Elliott AM, Bond CM, Hannaford PC, Chambers WA. The use of medication for chronic pain in primary care, and the potential for intervention by a practice-based pharmacist. Fam Pract 2006; 23: 46-52.

69 Needham DS, Wong IC, Campion PD, Hull and East Riding Pharmacy Developmnet Group. Evaluation of the effectiveness of UK community pharmacists' interventions in community palliative care. Palliat Med 2002; 16: 219-25.

70 Nishtala PS, Hilmer SN, McLachlan AJ, Hannan PJ, Chen TF. Impact of residential medication management reviews on drug burden index in aged-care homes: a retrospective analysis. Drugs Aging 2009; 26: 677-86.

71 Nishtala PS, McLachlan AJ, Bell JS, Chen TF. A retrospective study of drug-related problems in Australian aged care homes: medication reviews involving pharmacists and general practitioners. J Eval Clin Pract 2011; 17: 97-103.

72 Niquille A, Bugnon O. Relationship between drug-related problems and health outcomes: a cross-sectional study among cardiovascular patients. Pharm World Sci 2010; 32: 512-9.

73 Patterson SM, Hughes CM, Crealey G, Cardwell C, Lapane KL. An evaluation of an adapted U.S. model of pharmaceutical care to improve psychoactive prescribing for nursing home residents in northern ireland (fleetwood northern ireland study). J Am Geriatr Soc 2010; 58: 44-53.

74 Patterson SM, Hughes CM, Cardwell C, Lapane KL, Murray AM, Crealey GE. A cluster randomized controlled trial of an adapted U.S. model of pharmaceutical care for nursing home residents in Northern Ireland (Fleetwood Northern Ireland study): a cost-effectiveness analysis. J Am Geriatr Soc 2011; 59: 586-93.

75 Phelan M, Blenkinsopp A, Foster NE, Thomas E, Hay EM. Pharmacist-led medication review for knee pain in older adults: Content, process and outcomes. Int J Pharm Pract 2008; 16: 347-55.

76 Raynor DK, Nicolson M, Nunney J, Petty D, Vail A, Davies L. The development and evaluation of an extended adherence support programme by community pharmacists for elderly patients at home. Int J Pharm Pract 2000; 8: 157-64.

77 RESPECT trial team. Effectiveness of shared pharmaceutical care for older patients: RESPECT trial findings. Br J Gen Pract 2010; 60: e10-9. 
78 Ryan-Woolley BM, Cantrill JA. Professional perspective on a feasibility study of GP-pharmacist collaboration in the management of angina. Int J Pharm Pract 2000; 8: 275-84.

79 Schmidt I, Claesson CB, Westerholm B, Nilsson LG, Svarstad BL. The impact of regular multidisciplinary team interventions on psychotropic prescribing in Swedish nursing homes. J Am Geriatr Soc 1998; 46: 77-82.

$\mathbf{8 0}$ Schneider J, Barber N. Provision of a domiciliary service by community pharmacists. Int J Pharm Pract 1996; 4: 19-24.

81 Schulz M, Verheyen F, Muhlig S, Muller JM, Muhlbauer K, Knop-Schneickert E et al. Pharmaceutical care services for asthma patients: a controlled intervention study. J Clin Pharmacol 2001; 41:668-76.

82 Sellors J, Sellors C, Woodward C, Dolovich L, Poston J, Trim K et al. Expanded role pharmacists: Consulting in family physicians' offices - a highly acceptable program model. Can Pharm J 2001; 134: 27-31.

83 Sellors J, Kaczorowski J, Sellors C, Dolovich L, Woodward C, Willan A et al. A randomized controlled trial of a pharmacist consultation program for family physicians and their elderly patients. CMAJ 2003; 169: 17-22.

84 Shimp LA, Glazer HM, Reinke CM, Ascione FJ, Peggs JF, Reinhardt RW. A systematic approach to identifying and reducing medication-related problems in family practice patients. Fam Pract Res J 1986; 5: 247-54.

85 Soendergaard B, Kirkeby B, Dinsen C, Herborg H, Kjellberg J, Staehr P. Drug-related problems in general practice: results from a development project in Denmark. Pharm World Sci 2006; 28: 61-4.

86 Sorensen L, Stokes JA, Purdie DM, Woodward M, Elliott R, Roberts MS. Medication reviews in the community: results of a randomized, controlled effectiveness trial. $\mathrm{Br} J$ Clin Pharmacol 2004; 58: 648-64.

87 Stafford L, Stafford A, Hughes J, Angley M, Bereznicki L, Peterson G. Drug-related problems identified in post-discharge medication reviews for patients taking warfarin. Int J Clin Pharm 2011; 33: 621-6.

88 Stafford L, Peterson GM, Bereznicki LR, Jackson SL, van Tienen EC, Angley MT et al. Clinical outcomes of a collaborative, home-based postdischarge warfarin management service. Ann Pharmacother 2011; 45: 325-34.
89 Stergachis A, Fors M, Wagner EH, Sims DD, Penna P. Effect of clinical pharmacists on drug prescribing in a primary-care clinic. Am J Hosp Pharm 1987; 44: 525-9.

90 Stuijt CCM, Franssen EJF, Egberts ACG, Hudson SA. Appropriateness of prescribing among elderly patients in a Dutch residential home: observational study of outcomes after a pharmacist-led medication review. Drugs Aging 2008; 25: 947-54.

91 Towle I, Adams J. A novel, pharmacist-led strategy to reduce the prescribing of benzodiazepines in Paisley. Pharm J 2006; 276: $136-8$.

92 Villeneuve J, Genest J, Blais L, Vanier MC, Lamarre D, Fredette $\mathrm{M}$ et al. A cluster randomized controlled Trial to Evaluate an Ambulatory primary care Management program for patients with dyslipidemia: the TEAM study. CMAJ 2010; 182: 447-55.

93 Vinks THAM, Egberts TCG, de Lange TM, de Koning FHP. Pharmacist-based medication review reduces potential drug-related problems in the elderly: the SMOG controlled trial. Drugs Aging 2009; 26: 123-33.

94 Wermeille J, Bennie M, Brown I, McKnight J. Pharmaceutical care model for patients with type 2 diabetes: integration of the community pharmacist into the diabetes team - a pilot study. Pharm World Sci 2004; 26: 18-25.

95 Wilcock M, Harding G. What do pharmacists think of MURs and do they change prescribed medication? Pharm J 2008; 281: 163-7.

96 Wong C, Cave A, Jarman R. Pharmaceutical care in a family medicine centre. Can Pharm J 1997; 130: 35-43.

97 Yu K, Nguyen A, Shakib S, Doecke CJ, Boyce M, March G et al. Enhancing continuity of care in therapeutics: Development of a post-discharge home medicines review model. J Pharm Pract Res 2007; 37: 22-6.

98 Zermansky AG, Petty DR, Raynor DK, Freemantle N, Vail A, Lowe CJ. Randomised controlled trial of clinical medication review by a pharmacist of elderly patients receiving repeat prescriptions in general practice. BMJ 2001; 323: 1340-3.

99 Zermansky AG, Alldred DP, Petty DR, Raynor DK, Freemantle N, Eastaugh J et al. Clinical medication review by a pharmacist of elderly people living in care homes randomised controlled trial. Age Ageing 2006; 35: 586-91. 